\title{
AN EMPIRICAL INVESTIGATION ON THE IMPACT OF INCREASED FINANCING OF THE AGRICULTURAL SECTOR ON POVERTY REDUCTION, UNEMPLOYMENT AND ECONOMIC DEVELOPMENT IN NIGERIA
}

\author{
Nwabueze Prince OKENNA \\ Department of Economic Policy \& Development \\ Gilgal Economic Foundation \& Research Institute, Abuja Nigeria
}

\begin{abstract}
This research work investigated the impact of previous finances allocated to the agricultural sector has had on Nigeria's economic development and its contributions to poverty and unemployment rate reduction.

The research also investigated based on findings, the impact future increase in the financing of the sector would have on poverty reduction, employment generation, and economic development while identifying other potentials the agricultural sector has that can spur economic growth and development. Also, contributing to poverty reduction.
\end{abstract}

Based on the result and findings, various developmentfriendly policies and recommendations were proffered that when implemented, will contribute favourably in attracting investors both foreign and local, that could drive the needed change and desired outcome.

The work further identified and recommended other potentials the agricultural sector has that can impact positively on the country's existing potentials.

Keywords - Agriculture, Economic growth, Economic Development, Poverty, Unemployment, Nigeria.

\section{INTRODUCTION}

It is universally supported that the battle against the vicious systemic hunger and poverty circle is the fundamental requirement for sustainable long-term economic growth and development, poverty reduction, and employment generation especially in developing countries like Nigeria.

According to the TEconomics and Nigerian National Bureau of Statistics report of 2019, the contribution of the Agricultural sector to GDP of the country currently stood at 3.8million naira which is approximately 10.5thousand US dollars ranked as the 24th world's lowest GDP contribution from Agriculture.

According to the latest World Bank statistical report (2019), Nigeria is set to become the world poverty capital after recently overtaking India with about 86.9 million Nigerians living in extreme poverty which constitutes over $50 \%$ of her population. The unemployment rate of the country is also extremely alarming with close to $50 \%$ of her labour force unemployed and this rate keeps increasing.

In an economy like Nigeria, the agricultural sector had suffered severe setbacks attributed to insufficient funding, embezzlement of funds allocated to the sector, wrong policy formulations dues to inability to understand the root cause of the problem, poorly implementation of policies formulated among others.

Based on these, there is an urgent need for the government of Nigeria to diversify her economy now than ever by investing in the agricultural sector other than depending on petroleum products alone. An expansion in agricultural output as a result of an increase in government intervention through the Agricultural credit and grant scheme will bring about an increase in labour productivity, which would create jobs for the teeming unemployed youthful population, thus reducing poverty, make food available, etc. (NBS, 2016).

Poverty reduction and the fight against unemployment in Nigeria -and in general developing African countries can totally occur via planned intentionally, and deliberate attempts through drastic and strategic policies formulated that must be implemented which involves diversification and total overhaul of the agricultural sector. It is only when this is achieved that these unwelcomed tragic timed bombs orchestrated by unemployment and poverty in the country can be diffused. 
In view to the above established facts, it is expedient this paper explicitly explains some of the basic economic development theories that are aligned with developing countries of the world such as Nigeria.

\section{THE STRUCTURAL CHANGE ECONOMIC THEORY}

The Structural change economic theory also known as Lewis Model of structural economic growth and development was postulated by Arthur Lewis in his analysis and explanation of a dualistic economy -an economy that is composed of rural sector for agricultural activities and an urban sector for manufacturing activities.

The model elucidated strategies directed specifically at transforming the industrial and economic structures of developing countries. It summarizes steps needed and that should be undertaken by these nations that will facilitate their transformation from originally practicing subsistence agriculture to a more modern and industrial urbanized approach -Here, they will be equipped to not just producing for their own immediate consumption, but surpluses created should be exported which can be sold to other nations. This will create more jobs for the population and at the same time contribute to the gross domestic earnings of developing nations such as Nigeria.

In conclusion, the model is referred to as structural change model because it spells out strategies on how an economy can be transformed from being a mono-traditional economy to an industrial producing nation.

In its analysis, there are majorly two views of this theory.

1. The Lewis' two-sector surplus model, which sees predominantly agricultural nations/communities being composed of vast numbers of overabundance labour supply that could be employed to drive their advancement to an urbanized manufacturing sector.

2. Hollis Chenery's development approach which explains that several nations become developed through distinct attributes. The model a nation adopts should be dependent on its population size, landmass, and natural supplies, and conceivably its gross domestic products (revenue) in addition to her comparative advantage.

\section{THE LINEAR STAGES OF ECONOMIC GROWTH THEORY}

The linear stages of economic growth model also referred to as the "Rostow" stage of economic growth centers at the expedited aggregation and accumulation of resources mainly capital by making use of both national and foreign savings in driving her investments towards driving economic growth and development.
In its analysis, it posited that there are 5 stages of economic growth that all nations must go through (including developing countries) before they can achieve their set economic development goal/targets, and these are.

i. The traditional society stages. This is made up of mainly subsistence agricultural activities and production for sole/family consumption. It is assumed no country in the world is in this stage.

ii. The pre-conditions for the take-off stage. This is a stage where the community/nation are working towards putting in place several policies that would drive their development. This stage is characterized by the formulation of economic policies, models, and various modifications. In addition, all the necessary factors of production are being organized as well including the provision of basic facilities such as roads, electricity, internet and communication facilities, etc. An example of countries in this stage is Nigeria.

iii. The take off stage. This is the stage that precedes the pre-condition for take-off. This is a very short period of intensive growth that drives industrialization. At the stage, it is assumed that these policies and measures would have been implemented and formulated/approved by the respective institutions/agencies/authorities, including training of her workforce. In addition, it involves a drastic revolution and overhauling of both the political and technological areas of the country which are not limited to ensuring the participation of young and vibrant minds in the affairs of the country. An example of countries in this stage is Equatorial Guinea, Morocco, and Rwanda.

iv. The drive to maturity stage. Here, it is assumed that the workforce is now skilled, presence of economic and social security, high entrepreneurial activities and drive are the order of the day. In addition, there are adoption and utilization if the latest technologies. It is worth noting that at this stage, the pace of economic development is higher than population growth. Example of such countries in this stage is South Africa.

v. The stage of high mass consumption. At this stage, the economy is adequately developed and selfsustainable. Here, the country can produce and meeting the demand of its own population and even exports to other countries which increases their revenue and boosts the economy. In addition, scientific and technological development has reached 
its climax. Example of such a nation is the United States of America.

\section{HARROD DOMA ECONOMIC GROWTH THEORY}

The Harrod Domar economic growth model was explained in the 1930s and states that economic growth and advancements depend on the amount of labor force of the nation and her capital. Algebraically, this can be represented as GDP $=\mathrm{f}(\mathrm{K}$, L).

It further suggested that a higher proportion of savings made by the total population translate into a higher rate of investment that would create a self-sustaining economic growth for the nation.

In other words, developing countries such as Nigeria have a sufficient supply of labor force. Her economic development and advancement are caused by a lack of physical capital investment in basic strategic sectors with a higher multiplier effect on the economy such as in the agricultural sector.

\section{BRIEF OVER VIEW OF THE NIGERIAN ECONOMY VIZ-A-VIZ HER AGRICULTURAL SECTOR}

Despite the abundance of crude petroleum in Nigeria, the agricultural sector is still the predominant activity and foundation of her economy as it employs a significant amount of her population especially those in the rural parts of the country serving as their main source of income and livelihood. The agricultural sector has been faced with several challenges which have not been limited to the outmoded land tenure system, ineffective and in most cases absence of modern irrigation system, feeble adoption and implementation of findings from research owing to the high cost of agricultural implements, fertilizers, and many more.

Irrespective of these challenges in this sector, it is still considered as the most extensive sector of our economy employing over sixty per cent $(60 \%)$ of our labour force.

Within the last 20 to 25 years, the total value added by the agricultural sector to per-capital earnings has been insignificant because it has been less than $1 \%$ annually. In addition to this, Nigeria has lost approximately $\$ 10$ billion in the yearly international trading opportunities from major cash crops such as cotton, cocoa, groundnut, and red palm oil which was caused by the perpetual decrease in the cultivation, production, and extractions of these commodities (FOA United Nations, 2020).

It worth noting that there has been a play of the Malthusian population theory in recent decades as the population growth has significantly surpassed food production which has resulted in a continuous spike in food importation -our over-reliance on these importations as a quick way out has significantly contributed to the crippling effects of the economy of the country and there have been one of the major setbacks and obstacles that has hindered the development of the agricultural sector (FMARD, 2008).

The major factors that have consistently threatened the development of this sector which I believe that the government and the respective development policy agencies should channel a substantial amount of funds allocated to this sector to resolve are inadequate seedlings (modernized seedlings), absence of agricultural extension services, loans (grants) at reduced interests, farm inputs and implements such as tractors, harvesters etc. The agricultural sector should be made more attractive to the labour force just the way oil sectors are -it is only when it has been made attractive that the youths of the country will deem it necessary to venture into. The investments, funds, and partnerships generated should be geared towards modernizing and mechanizing the agricultural sector.

Nigeria is Africa's major rice consumer on the continent, and also one of its largest producers, and one the highest rice importer of rice in the whole world.

It is worth noting that rice production is one of the fast-selling and one the highest consumable cash crop in the country predominantly cultivated by small-scale farmers with the use of local farm implements such as the hoe, and cutlass under harsh farming conditions such as limited access to irrigation, localized processing types of equipment, etc.

In 2008 , the total tone of milled rice produced by the country is approximately 2 million metric ton, while a rough estimate of about 3 million metric tons was imported into the country with about 800thousand MT estimated to be the annual illegal import of rice (NBS, 2010).

Aside rice, Nigeria is the world's largest producer of cassava. She produces approximately 50million MT annually from a cultivated area of about 3.7 million hectares out of an estimated arable land of about 82 million hectares. Going by these statistics, Nigeria uses just about $4.7 \%$ of its arable land in the cultivation of cassava -this is an under-utilization of her available resources owing to lack of adequate financing caused by negligence and abandonment of the agricultural sector (FAO, 2019).

The fishery sector of Nigeria contributes approximately $4 \%$ annually to the country's gross domestic product and revenue. It is also a major source of protein (nutritional benefit) to both the people and also in the formulation of animal feeds -animal husbandry farming.

It is paramount to state that it is both a significant source of income and employment to a vital proportion of the population of the labour force.

Irrespective of the gradual decline in capturing fishes due to global environmental warming/change, the country still has 
tremendous potentials in this sub-sector due to the vast fresh and marine water around us.

Despite all these potentials and comparative advantages, her fish production has still been unable to meet her population demand -relying on further importation into the country with a rough estimate of about 2.2 million MT annually -this is about $60 \%$ of the total fishes consumed in the country.

To overcome this challenge, there is a dire need for the country to invest in aquaculture -this is not limited to training and re-training of both new and old interest fish farmers and the younger population.

Animal Husbandry is also a major part of the agricultural sector of Nigeria. Approximately, 30\% of livestock eaten in Nigeria are imported into the country from neighboring nations such as the Niger Republic. Similar to other subsectors, this area is stifled with breeds that are of low productivity and takes a longer time to grow and yield productivity owing shortage of feeds, arable grazing land, diseases, and many more.

Achieving full productivity from this subsector requires urgent and deliberate investment and commitments from the government and all concerned agencies.

\section{RELATED WORK}

Various studies have been conducted by various economists to analyse the relationship that exists between agriculture and economic development viz-a-viz employment generation. However, only a few of these studies examined this relationship in line with poverty reduction, and how the agricultural sector can be effectively financed to contribute and become the key driver of macroeconomic growth and development needed in the country.

In 2007, Kwa and Bassoume investigated the relationship between the exportation of agricultural products and sustainable economic development. In their study, various countries were analysed who are major exporters and they discovered there existed a positive direct relationship between sustainable economic development and increased agricultural exports especially cash crops.

A similar study was conducted in 2010 by Sanjuana-Lopez and Dawson where they evaluated the potential contribution and effects of exportation of agricultural products on macroeconomic growth in emerging countries like Nigeria.

In the result of their analysis from the estimation of the relationship between GDP and agricultural and nonagricultural exports using a Panel cointegration estimation method from 13 countries analysed out of 42 underdeveloped nations, there existed long-term links between agriculture and the non-agricultural exports. Hence, it was concluded that poor nations should embrace balanced exportation promotion strategies as this has the potentials of significantly contributing to their desired macroeconomic growth and development.

In 2017, an experiential analysis of the effects of constant positive change of economic reforms and the liberalization of economic trading policies on agricultural exports on economic development in Pakistan was conducted by Nadeem. Here, he equally examined the effect of the internal supply-side factors and external market demands on the economy. From his findings, diversification of agricultural productions and trading contributes significantly to the openness of the economy which attracts investment and subsequently, economic development.

This research will adopt a more modified strategy by utilizing the Ordinary Linear regression estimation due to its BLUE properties as being the best linear unbiased estimator. With the idea gotten from Harod-Dommar model, the linear model was modified to include some fundamental variables such as technique through the incorporation of differenced time series data and parameters such as interest rate, exchange rate, economic growth mode used to capture economic development, unemployment rate, and agricultural sector contribution to GDP obtained from the Central Bank of Nigeria statistical bulletin, and National Bureau of annual statistics.

\section{METHODOLOGY}

The paper adopted the Ordinary least Square (OLS) estimation technique owing to its BLUE properties as the best linear unbiased estimator.

To prevent spurious regression results, all the data collected were subjected to various statistical tests such as the ADF test (Augmented Dickey-Fuller) for stationarity, unit root test, Ttest, F-test, Johansen co-integration test and Durbin Watson (DW) test.

It is pertinent to note that time-series data was used for this research work and was obtained from the Central Bank of Nigeria (CBN) annual statistical bulletin. The data collected covered a period of 26 years (1995 to 2019) -this is to allow enough time for deep analysis and to arrive at a proposed resolution and policies to address the issue of financing in the agricultural sector and its role in economic development and nation-building of Nigeria.

\section{MODEL SPECIFICATION}

This study adopted the Harrod Domar economic growth theory in its model specification. However, this model/theory was modified to incorporate other basic variables in its analysis such as Unemployment rate, exchange rate, and interest rate in Nigeria obtained from the World Bank labour 
force index for Nigeria, Central Bank statistical report, and the National Bureau of Statistics 2020 report.

The linear relationship between Economic growth by RGDP, Agriculture Sector Contribution to GDP, Interest rate, Unemployment rate, and Exchange rate is expressed algebraically below.

\section{$\mathrm{ECGR}=\mathrm{F}(\mathrm{ASCGDP}, \mathrm{INTR}, \mathrm{UEMPR}, \mathrm{EXHR})$}

$\log \mathrm{ECG}=\beta 0+\beta 1 \log$ ASCGDPt $+\beta 2 \log$ INTRt $+\beta 3 \log$ UEMPRt-1 + $\beta 4$ EXHRt- $1+\mu \mathrm{t}$

Where;

ECGR = Economic Growth by real gross domestic product ASCGDP = represents gross domestic product,

INTR $=$ Interest Rate

UEMPR = Unemployment Rate

$\mathrm{EXHR}=$ Exchange Rate

$\beta_{0}=$ the constant term,

$\beta_{1}=$ the parameter estimates of ASCGDP

$\beta_{2}=$ the parameter estimates of INTR

$\beta_{3}=$ the parameter estimates of UEMPR

$\beta_{4}=$ the parameter estimates of EXHR

$\mu_{\mathrm{t}}=$ stochastic term

Testing the hypothesis that:

$\mathrm{H}_{0}$ : Increased finance of the agricultural sector will significantly (positive) impact on poverty reduction, job creation and economic development in Nigeria

$\mathrm{H}_{1}$ : Increased finance of the agricultural sector will not have any positive impact on poverty reduction, job creation, and economic development in Nigeria.

\section{STATISTICAL CRITERIA}

This aims at evaluating the statistical reliability of all the data being estimated. The basis of this is to prevent misleading results. This was evaluated using the F-statistics, t-statistics, Co-efficient of determination (R2), and the Adjusted R2.

\section{PRESENTATION AND ANALYSIS OF UNIT ROOT TEST}

For strait-laced analysis of the impact of the increased finance of the agricultural sector on poverty and unemployment reduction as well as economic development in Nigeria, the statistical tests below were carried out.

Table 1.0. Showing ADF Unit Root test (Eviews 10)

From the Unit root test conducted using Econometrics View 10 software, it can be deduced that all the parameters to be used for this analysis are stationary at their first difference level as the absolute value of their respective values are greater than the critical values at both $5 \%$ and $10 \%$.

\section{PRESENTATION AND ANALYSIS OF REGRESSION RESULT}

\begin{tabular}{|l|l|l|l|l|l|}
\hline Series & $\begin{array}{l}\text { ADF } \\
\text { test }\end{array}$ & $\begin{array}{l}5 \% \\
\text { critical } \\
\text { values }\end{array}$ & $\begin{array}{l}10 \% \\
\text { critical } \\
\text { values }\end{array}$ & Order & Remark \\
\hline ECGR & -6.621 & -3.0134 & -2.932 & $1(\mathrm{I})$ & stationary \\
\hline ASCGDP & -5.895 & -3.0134 & -2.932 & $1(\mathrm{I})$ & stationary \\
\hline INTR & -6.345 & -3.0134 & -2.932 & $1(\mathrm{I})$ & stationary \\
\hline UEMPR & -6.004 & -3.0134 & -2.932 & $1(\mathrm{I})$ & stationary \\
\hline EXHR & -5.956 & -3.0134 & -2.932 & $1(\mathrm{I})$ & stationary \\
\hline
\end{tabular}

The regression result of the variables and parameters estimated using the OLS distributed lag method is presented below

\begin{tabular}{|c|c|c|c|c|c|c|}
\hline Variable & $\begin{array}{c}\text { Coefficien } \\
t\end{array}$ & Std. error & t.stat & $\mathrm{R}^{2}$ & DW & F.Stat \\
\hline Constant & 13.21 & 0.851 & 24.005 & \multirow{5}{*}{0.96} & \multirow{5}{*}{1.73} & \multirow{5}{*}{278.5} \\
\hline ASCGDP & 20.56 & 3.781 & 6.354 & & & \\
\hline INTR & 8.36 & 0.473 & -2.838 & & & \\
\hline UEMPR & -21.20 & 2.798 & -2.462 & & & \\
\hline EXHR & 4.1622 & 4.002 & 8.870 & & & \\
\hline
\end{tabular}

Table 1.1. Showing the regression result (Eviews 10)

\section{INTERPRETATION OF REGRESSION RESULTS}

The estimated regression result is seen and explained below;

$\mathrm{ECG}=13.21+20.56 \mathrm{ASCGDP}+8.36 \mathrm{INTR}-21.20 \mathrm{UEMPR}+$ 4.16EXHR

From the estimated equation above,

There existed a positive relationship between the Agricultural Sector Contribution to GDP (ASCGDP), interest rate (INTR), and Exchange rate (EXHR) with economic growth (ECG). While on the other hand, there existed a negative relationship between economic growth (ECG) and unemployment rate (UEMPR).

The R-squared which is $0.96(96 \%)$ indicated there is the goodness of fit among the variables analysed.

\section{RESULTS AND DISCUSSION}

The result obtained from the estimated equation showed a direct proportional relationship between economic growth (ECG) that denotes a proxy to measure economic development that would be triggered by the agricultural sector and the Agricultural Sector Contribution to GDP (ASCGDP), interest rate (INTR), and Exchange rate (EXHR). On the other hand, 
there was an inverse relationship between economic growth (ECG) and unemployment rate (UEMPR).

In reality, a percentage increase in economic growth (ECG) orchestrated by increased finance of the agricultural sector by the concerned bodies will lead to a proportionate increase in Agricultural Sector Contribution to GDP (ASCGDP) by 20.56 per cent, Interest rate by 8.36 per cent, and exchange rate by 4.16 per cent. While on the other hand, a proportionate increase in Agricultural Sector Contribution to GDP (ASCGDP) by 20.56 per cent will lead to a decline in the unemployment rate in the country by 21.2 per cent.

The R-square which measures the level of variation of the regressed data is at $0.96(96 \%)$. The implication of this is that $96 \%$ of the cumulative variation of economic growth (ECG) that denotes a proxy to measure economic development is explained by the variation in Agricultural Sector Contribution to GDP (ASCGDP), interest rate (INTR), the Exchange rate (EXHR), and Unemployment rate (UEMPR). While only $4 \%$ is accounted for by other variables not indicated in the model estimated which was represented in the model by the error term $(\mu)$. The R-square result also indicated that the regression has high goodness of fit.

\section{POLICY IMPLICATION}

Availability of funding and investments (both internally by the government and other organizations and externally by reputable institutions) is an indispensable component that is needed in the development of most sectors and subsectors in any economy that has a high multiplier effect to development this is what the agricultural sector is and has been to the economies of developed nations.

There is a dire need that such is replicated here in our country as against what has been prevalent here in Nigeria. It is also pertinent to point that within the last 2 years, the government's financial contributions and budgets allocated to this sector have declined by over $20 \%$. This path will not and cannot bring in the much-needed economic objective and transformation that is being clamoured for in the country.

There are several factors that the government of Nigeria needs to put into consideration as a necessity for the agricultural sector to yield and drive this drastic change in the economy such as realizing that the financial sectors are significant drivers to this course. This undoubtedly implies that all feasible regulations, policies, and players needed to attract investments and funding to this sector must be realistic especially international investors.

In the implementation of these policies and execution of these programs, a holistic approach must be taken to ensure food, employment generation, poverty eradication to the barest minimum are channelled towards the marginalized groups in the economy with no exception of the rural and small scale farmers so as to create a win-win-win agricultural financing scheme for all.

\section{LIMITATION AND FUTURE SCOPE}

During our investigation and research, we encountered numerous constraints such as data availability and proxies used that could be used to measure certain impacts/variables such as a measure for economic development -here, gross domestic product was used. This is a limitation as GDP doesn't capture economic development. Rather, it measures economic growth.

Other challenges include the availability of accurate data from the Nigerian agricultural institutions.

Future research and studies on similar subject might be impacted if these issues are not resolved. One of such is that the various institutions and agencies responsible for accurate data collection and analysis should be put up to speed and possibly revamped to ensure accurate data are made available to researchers as results gotten will immensely contribute towards the formulation and implementation of macroeconomic policies and projects in the country.

\section{POLICY RECOMMENDATIONS}

In a bid to increase agricultural contributions and output to eradicate poverty and reduce unemployment in Nigeria while simultaneously contributing to economic development, this study recommends the following;

1. The government should strive towards modernizing and mechanizing the agricultural sector. At the moment, over $80 \%$ of farm produce and farmers engaged in agricultural activities are still relying on the use of the crude traditional farming implements in the cultivation and harvesting of their produce such as hoe, spade, etc.

In this $21^{\text {st }}$ century, this shouldn't be the order of the day it has been proven that this sector has the capacity and potential of driving the needed results and sustainable economic development goals needed in the country -the agricultural sector should be treated as such. It must be given the same attention that oil/petroleum sector is given in the country.

Based on this, the study recommends modernization and immediate mechanization of the sector through the purchase and distribution of equipment's such as tractors, harvesters, etc. this will not just boost production and increase output, it will also lead to increased revenue both to the government as well as the farmers.

2. Adequate finance should be made readily available to farmers who needs such and at reduced interest rate and good moratorium period. This is to act as a shock absorber caused by the uncertainty in this sector such as bad weather condition, infection, diseases etc. This study further recommends that these finances should not only be 


\section{International Journal of Engineering Applied Sciences and Technology, 2020 \\ Vol. 5, Issue 3, ISSN No. 2455-2143, Pages 75-82 \\ Published Online July 2020 in IJEAST (http://www.ijeast.com)}

targeted to large scale farmers, but to small-scale farmers as well to encourage them and at the same time, this would contribute to their expansion. The idea is due to the fact that this sector has a higher multiplier effect that every other sectors and subsectors of the country.

The current agricultural financial activities and intervention funds of the Central Bank of Nigeria is a great idea and should be sustained. However, we need to ensure that these funds are not being hijacked by some politicians who will apply for such funds and it gets approved only be used for other purpose such as investing it in banks. This will defeat the aim of these intervention funds -this study therefore proposes a transparent allocation and audit of these funds on a quarterly basis. This is to track the progress and ensure it is effectively managed and not misappropriated. Hence, an independent non-partisan auditing body/committee be setup to monitor, audit and publish their findings and progress of these intervention funds by the being disbursed by the government through the Central Bank of Nigeria and equally, other national or international donor agencies.

3. There should be an effective and efficient transportation system that would convey farm produce from the farm to the market or various points where these produces will be picked up or sold. At the moment, most of the rural farmers are responsible for transporting their farm produce to the market using rickety means of transportation and this damages the farm produce reducing their value. This paper proposes that this part should be handled by a local government constituted agency in the rural locations after harvest. This will not only reduce the cost incurred by these farmers, it will also ensure the value of these produce are preserved -this will also command a great market value as against when they are damaged.

4. The government should regularly provide extension services to these farmers. These services include training and retraining of the farmers on current agricultural practices and methods. These trainings include current cultivation methods, improved seedlings, harvest, irrigation, and advantages of using them. A vast majority of these farmers are in the rural areas and unexposed to modern farming practice methods. The government should take this as a core responsibility to train these farmers on the best agricultural practice methods. It is also pertinent to note that these services will create jobs for the agricultural extension workers, and in the long run, the farmers will be adequately equipped which will increase output, reduce cost of production, and subsequently revenue generated.
5. The study further proposes that modern farm inputs such as seedlings, fertilizers, pesticides, etc should be made readily available to these farmers at subsidized rates. We understand that the government of Nigeria has suspended the subsidies paid to the petroleum sector. We further propose that these funds should now be channeled towards subsidizing the agricultural sector. This will go to great extent in making the agricultural sector more attractive and profitable not just for the farmers themselves, but also for the younger generation and unemployed population -contributing to poverty reduction and employment generation.

6. The agricultural sub-sectors should also be revamped and taken seriously by the government. Deliberate actions should be taken to develop and make it attractive. Some of these sectors include fishery, animal husbandry, snail farming, etc. The reason behind this is because these sectors are inter-related and inter-twined amongst themselves. An improvement in this sector rubs off on the other and vice-versa.

\section{CONCLUSION}

In conclusion, this paper explicitly advices this government that the agricultural sector's capacity and potentials to reduce poverty, increase revenue, creates employment, revenue generation, and economic development is dependent on a conscious and consistent supports from the government which borders around agricultural inputs, output supports, technical, and financial supports.

In summary, the agricultural inputs practically relate to provision of resources that would make cultivation worthwhile. These are not limited to improved seedlings, fertilizers, pesticides, insecticides, etc. The agricultural output supports denotes actions that the government must take to protect the harvest and yields of these farmers so as to preserve their value, ensure retained profit -this may also include provision of storage and processing facilities to preserve excess products.

In terms of technical supports, this involves training and retraining of the farmers on modern agricultural best practice methods such as extension services, use of modern farm implements such as tractors, harvesters etc. While the financial supports involve provision of grants, long-term soft loans, financial planning and education to the farmers as well price control.

\section{ACKNOWLEDGMENT}

All gratitude and thanks to God for the grace and knowledge He bestowed on me. It is a great privilege to share my thoughts 
and contributions to existing body of knowledge out there through this medium.

\section{REFERENCE}

[1] CBN (2019). Annual Report available at https://www.cbn.gov.ng//

[2] Chenery, Hollis B. (1975). The Structuralist Approach to Development Policy, American Economic Review, American Economic Association, vol. 65(2), (pages 310316).

[3] Federal Ministry of Agriculture \& Rural Development FMARD (2016). Nigeria's Staple Crop Processing Zones".

[4] Haque, Nadeem \& Kemal, Muhammad. (2007). Impact of Export Subsidies on Pakistan's Exports. Available at 10.2139/ssrn.991513.

[5] Haque, Nadeem. (2018). Macroeconomic Research and Policy Making: Processes and Agenda.

[6] Kwa and Bassoume (2007). Exploring the Linkages between Agricultural Exports and Sustainable Development. Ecofair trade dialogue, (Pg1-38).

[7] NATIONAL BUREAU OF STATISTICS, (2019): Nigeria poverty Profile Report. Abuja Nigeria.

[8] NBS, (2019). Poverty and Inequality in Nigeria 2019: Available at: https://nigerianstat.gov.ng/elibrary?queries[search]=pover ty

[9] Rostow, W. W. (1960). The Stages of Economic Growth: A Non-Communist Manifesto.

[10] Sanjuan-Lopez, A.I. and Dawson, P.J. (2010). Agricultural Exports and Economic Growth in Developing Countries: A panel Co-Integration Approach. Journal of Agricultural Economics, (pg565-583).

[11] Lewis, D. Gollin (2014). The Lewis Model: A 60-Year Retrospective Douglas Gollin, The Journal of Economic Perspectives, (Pg71-88).

[12] UN Food and Agriculture Organization (FAO), (2019). Regional Reports on Africa Regional Overview of Food Insecurity in Africa.

[13] World Bank Report (2020). Available at http://databank.worldbank.org/data/reports.aspx?source=2 $\underline{\text { \&country }=\mathrm{NGA}}$

[14] World Bank World Development Report (2008). Agriculture for Development. Washington, D.C. 